\title{
NEGATIVE AND HELPFUL STATEMENTS IN A PATIENT ONLY OR THERAPIST GUIDED INTERNET FORUM IN THE AFTERCARE FOR PSYCHOSOMATIC INPATIENTS
}

\author{
Michael Linden \& Carolin Pirsich \\ Research Group Psychosomatic Rehabilitation, Charité University Medicine Berlin, Berlin, Germany \\ received: 9.5.2017; \\ revised: 28.8.2017; \\ accepted: 15.9.2017
}

\begin{abstract}
SUMMARY
Background: The aftercare of patients in the wake of inpatient treatment is a therapeutic challenge. Aim of the present study was to investigate the utilization, and positive or negative interactions in a patient only (PF) and a therapist guided internet forum (TF) in the follow up of psychosomatic inpatient treatment.

Subjects and methods: After discharge from hospital, patients were offered to participate in a PF or TF. The rate and duration of participation was monitored and the content of communication classified by content analysis.

Results: In the PF 144 (8.0\%) and in TF 76 (8.5\%) of invited patients registered. Participants were somewhat younger, more often male, and professionally better qualified. Time of participation was 51 (sd 90) days in the PF and 59 (sd 69) in the TF. 32\% of the registered patients wrote messages in the PF and 43\% in the TF, with 7 (sd 10) comments on average in the PF and 15 (sd 26) in the TF. Most comments were health related and positive, with a higher rate in the TF. There were still 8 destructive comments in both forums.

Conclusions: The rate of participation in the aftercare internet forum is low. Therapeutic guidance increases the rate of patient contributions. Most comments are supportive, but negative interactions occur even in the presence of a moderator.
\end{abstract}

Key words: self help groups - patient support groups - internet groups - mental disorders - after care

$$
* * * * *
$$

\section{INTRODUCTION}

The aftercare of patients following inpatient treatment is important for sustaining treatment effects (Smith et al. 2016, Fullerton et al. 2016). Most patients will not be fully remitted after a hospital stay so that further care is necessary. It is a responsibility of therapists in the hospital to plan the discharge of patients and make sure, that they are properly treated afterwards. Follow up treatment can be done by other physicians or institutions. For a transition period it can also be done by the hospital, until the outpatient care can take over. An interesting option is to keep in contact with patients via internet. This can be done either by therapist contacts but also by patient self-help groups.

Self help groups are in general an important element in health care. Participants have similar experiences with their illness and can teach each other on how to cope with it. They can give each other support, facilitate contact with other people, which is sometimes difficult for persons with health problems and can be a possibility to prevent relapse (Neto \& Silva 2008, Schmädeke \& Bischoff 2015). There are self help groups with patients only, but also groups with professional support or guidance. They can meet regularly, or on demand, or by special prior arrangements. Apart from meeting eye to eye, the internet plays an increasing role in patient exchanges and education. There is evidence, that internet based self help groups can have effects, similar to face-to-face-groups (Keating \& Rains 2016, Andersson $\&$ Titov 2014). Internet patient groups give the possibility to extend care especially after inpatient treatment, as patients have been together in the hospital, can stay in contact, or also interact with known therapists.

Patient interactions should be supportive, induce optimism, give helpful advice, or induce recreational activities (Pfeiffer et al. 2011). But, it can also be that wrong advice is given, conflicts arise, or hopelessness is induced. The question of positive or negative exchanges is of special importance for internet groups, as the possible anonymity easily allows to 'express oneself' or become ruthless, up to 'flaming', 'cyberbullying', or even advice on how to commit suicide (Sendula-Jengic et al. 2016, Speed et al. 2016, Aboujaoude et al. 2015, Alonzo $\&$ Aiken 2004). They may also be infiltrated by special interest groups or persons with special agendas (Holtz et al. 2012). Furthermore, patients with psychological problems could be inclined to engage in negative interactions. Such negative interactions may be a problem in 'patient only' groups. If such groups are moderated by professionals, patient interaction should be guided to be positive and detrimental interactions should be suppressed (Griffiths et al. 2015, Klemm 2012, Castelein et al. 2008, Schielein et al. 2008).

There is a need for research on the acceptance of internet groups in the aftercare of inpatient treatment, and even more so on positive or negative comments in such internet contacts (Mo \& Coulson 2008, Ginossar 2008, Love et al. 2012, Gilat et al. 2012, Yoo et al. 2013). Aim of the present study was to investigate the utilization, and positive or negative interactions of patients, suffering from non-psychotic mental disorders, in a 'patient only (PF)' or a 'therapist guided aftercare internet patient forum (TF)'. 


\section{SUBJECTS AND METHODS}

\section{Patients and internet forum}

Patients were recruited from a department of behavioral medicine. During their inpatient treatment all patients got individual and group psychotherapy and were also stimulated to meet in patient self-help groups. Tabele 1 summarizes patient characteristics, like sociodemographic details, the overall severity of symptoms at discharge from the hospital as measured with the SCL90 (Franke 1995), and the spectrum of diagnoses.

An internet forum was set up to support contacts between patients after discharge from the hospital. Patients could open this forum everyday for twenty four hours and post whatever they wanted. This could be read by others who could comment on it or not. This is different from internet chat rooms where patients have to be online at the same time. Patients had the possibility to contact a therapist directly in cases of urgency.

All patients who came to inpatient treatment were informed about this forum. They got an identification number and technical advice on how to use the forum. This forum was open only to former patients of the hospital. Patients could participate either anonymously or with a nick name or with their full name, whatever they preferred. Informed consent was obtained from all participants of the study. The study was in accordance with the ethical standards of the Helsinki Declaration.

For two years a patient only forum (PF) was run. The next year the method was changed and a social worker participated actively as moderator and guided the exchange between the patients (TF). The social worker could be recognized by her full name and was known to everybody from the time in hospital. She had had individual contacts with the patients and had also run therapeutic groups. The moderator engaged in the exchange, but also stimulated topics about what one could write.

\section{Content analysis}

A content analytic category system was developed to count the frequency and content of postings (Früh 2007). Main dimensions were the quality (e.g. positive, negative), content, group interaction and self disclosure. Reliability of categorizations was good, with Cronbachs-Alpha-coefficients ranging between $\mathrm{r}=0.82$ and $\mathrm{r}=0.95$.

\section{RESULTS}

\section{Participation}

During the PF period 1842 patients were informed about the forum. $8 \%$ logged in and from these $32 \%$ wrote comments. During the TF period 893 patients were informed. $8.5 \%$ logged in and $43 \%$ wrote comments. Table 1 summarizes patient characteristics for both groups divided for patients who logged in or not. Participants were somewhat younger, more often male, and professionally better qualified.
In the PF patients participated on average 51 $(\mathrm{SD}=90)$ days and in the TF $59(\mathrm{SD}=69)$ days $(\mathrm{t}=-0.39$; $\mathrm{p}=0.69)$. Participants in the $\mathrm{PF}$ wrote on average 7 $(\mathrm{SD}=10)$ comments, and the 33 in the TF $15(\mathrm{SD}=26)$, which is somewhat but not significantly more $(\mathrm{t}=-1.67$; $\mathrm{p}=0.10$ ). Most patients participated anonymously i.e. $89 \%$ in the patient only and $88 \%$ in the moderated forum. All patients wrote more responses to comments of others (patient only: $4.87, \mathrm{SD}=8.1$; moderated: 12.64 , $\mathrm{SD}=2.4$ ) instead of bringing in new topics (patient only: 1.91, $\mathrm{SD}=2.4$; moderated: $2.12, \mathrm{SD}=2.1 ; \mathrm{F}=14.65$, $\mathrm{p}<0.01)$. In both forums most comments were made in the evening hours and with some time delay (patient only: $96 \%$, moderated: $79 \% ; \chi^{2}=5.99 ; p=0.05$ ).

\section{Content of comments}

Most comments were health oriented, i.e. across all items of table 2 on average per active patient 27.3 $(\mathrm{SD}=39.5)$ in the $\mathrm{PF}$, and $73.1(\mathrm{SD}=129.5)$ in the $\mathrm{TF}$. Small-Talk-comments are only $1.2(\mathrm{SD}=3.5)$ on average in the $\mathrm{PF}$, and $1.0(\mathrm{SD}=1.9)$ in the $\mathrm{TF}$, which is significantly less than the health oriented comments $(\mathrm{F}=24.40 ; \mathrm{p}<0.01)$.

The type of forum makes a significant difference in respect to the amount and spectrum of topics with more health supportive comments and less small talk in the TF (MANOVA between groups $\mathrm{F}=4.88$; $\mathrm{p}<0.05$; interaction $\mathrm{F}=5.39 ; \mathrm{p}<0.05)$. Table 2 shows the average number of comments for single topics in comparison of $\mathrm{PF}$ and TF. In the TF there are significantly more comments in respect to 'symptoms' $(\mathrm{F}=5.47 ; \mathrm{p}<0.05)$, 'coping' $\quad(\mathrm{F}=6.81 ; \mathrm{p}<0.05), \quad$ 'self-perception' $\quad(\mathrm{F}=4.6$; $\mathrm{p}<0.05)$, 'leisure time' $(\mathrm{F}=4.74 ; \mathrm{p}<0.05)$, 'work' $(\mathrm{F}=6.84$; $\mathrm{p}<0.05)$, 'money' $(\mathrm{F}=5.32 ; \mathrm{p}<0.05)$ and 'social relations' $(\mathrm{F}=7.36 ; \mathrm{p}<0.01)$. No differences were seen for 'retirement' $\quad(\mathrm{F}=0.16 ; \mathrm{p}>0.05), \quad$ 'hospital' $\quad(\mathrm{F}=1.95$; $\mathrm{p}>0.05)$, 'personal biography' $(\mathrm{F}=3.67 ; \mathrm{p}>0.05)$, 'comments on the forum' $(\mathrm{F}=2.75 ; \mathrm{p}>0.05)$, and 'offline contacts' $(\mathrm{F}=0.03 ; \mathrm{p}>0.05)$.

\section{Group interaction}

In both forums patients write about group cohesion, self-disclosure, emotional support, or give supportive information. There are significantly more such comments in the TF (MANOVA for independent samples, Pillai $=0.14 ; \mathrm{F}=3.10 ; \mathrm{p}<0.05)$. Univariate post-hoc-Ftests showed significantly higher rates for 'cohesion' and 'emotional support', and a trend for 'self-disclosure' in the TF, with no difference for information.

\section{Emotional quality of comments}

Figure 1 shows that in both forums the majority of comments were constructive or neutral to positive. Destructive comments were rare with only 8 comments from 2 patients. They occur in both forums. A MANOVA for independent samples showed significant overall differences between the two forums (Pillai $=0.12 ; \mathrm{F}=2.54$; $\mathrm{p}<0.05)$ and in univariate post-hoc-F-tests significantly 
Table 1. Patients in the PF and TF divided for participants and non-participants

\begin{tabular}{|c|c|c|c|c|c|c|}
\hline & \multicolumn{3}{|c|}{$\mathrm{PF}$} & \multicolumn{3}{|c|}{$\mathrm{TF}$} \\
\hline & $\begin{array}{c}\text { non- } \\
\text { participants } \\
n=1698\end{array}$ & $\begin{array}{c}\text { participants } \\
n=144\end{array}$ & $\begin{array}{c}\text { t-test } \\
\chi^{2}\end{array}$ & $\begin{array}{c}\text { non- } \\
\text { participants } \\
\mathrm{n}=817\end{array}$ & $\begin{array}{c}\text { participants } \\
\mathrm{n}=76\end{array}$ & $\begin{array}{c}\text { t-test } \\
\chi^{2}\end{array}$ \\
\hline Age (M, SD) & $46.9(8.7)$ & $45.4(8.7)$ & $-2.06^{*}$ & $46.8(8.2)$ & $43.6(10.3)$ & $-2.62 *$ \\
\hline Female $(\%)$ & 76.0 & 62.5 & $12.82 * *$ & 76.0 & 72.0 & 0.54 \\
\hline Profession $(\%)$ & & & $22.31 *$ & & & $22.19 *$ \\
\hline Unlearned. Worker & 3.1 & 0.0 & & 3.0 & 8.0 & \\
\hline Low level employee & 20.6 & 13.2 & & 23.4 & 18.4 & \\
\hline Middle level employee & 55.2 & 57.0 & & 53.0 & 47.4 & \\
\hline High level employee & 14.0 & 23.5 & & 12.4 & 13.2 & \\
\hline Superior employee & 2.0 & 1.4 & & 2.7 & 3.9 & \\
\hline Independent & 3.5 & 3.5 & & 3.8 & 3.9 & \\
\hline Others / unknown & 1.7 & 1.4 & & 1.7 & 5.2 & \\
\hline SCL-90 GSI (M, SD) & $0.83(0.68)$ & $0.81(0.67)$ & -0.27 & $0.76(0.64)$ & $0.75(0.76)$ & -0.05 \\
\hline ICD-10 (\%) & & & $\chi^{2}$ & $\%$ & $\%$ & $\chi^{2}$ \\
\hline F0, organic disorders & 4.5 & 7.6 & 3.72 & 2.8 & 1.3 & 0.59 \\
\hline F1, substance abuse & 9.8 & 7.7 & 0.81 & 7.0 & 6.6 & 0.37 \\
\hline F2, schizophrenia & 1.5 & 1.4 & 0.02 & 1.5 & 1.3 & 0.01 \\
\hline F3, affective disorders & 32 & 35.4 & 0.81 & 31.0 & 27.6 & 3.58 \\
\hline $\mathrm{F} 4$, reactive and anxiety disorders & 60.4 & 55.6 & 2.89 & 58.0 & 61.8 & 0.50 \\
\hline F5, behavioral syndromes & 3.5 & 2.8 & 0.34 & 3.1 & 2.6 & 0.04 \\
\hline F6, personality disorders & 14.2 & 18.8 & 2.42 & 14.3 & 17.1 & 0.43 \\
\hline F7, mental retardation & 0.4 & 0.7 & 0.41 & 0.1 & 0.0 & 0.09 \\
\hline F8, developmental disorders & 1.1 & 1.4 & 0.09 & 3.6 & 1.3 & 1.15 \\
\hline F9, behavioral disorders & 0.9 & 1.4 & 0.27 & 1.3 & 1.3 & 0.00 \\
\hline
\end{tabular}

Table 2. Total number of health supportive comments for active participants of the patient only and moderated forum

\begin{tabular}{|c|c|c|c|}
\hline & $\begin{array}{c}\mathrm{PF} \\
\mathrm{n}=46 \\
\mathrm{M}(\mathrm{SD})\end{array}$ & $\begin{array}{c}\mathrm{TF} \\
\mathrm{n}=33 \\
\mathrm{M}(\mathrm{SD})\end{array}$ & F-Test \\
\hline \multicolumn{4}{|l|}{ Content of postings } \\
\hline Hospital & $5.15(6.91)$ & $7.88(10.44)$ & 1.95 \\
\hline Symptoms & $5.07(6.80)$ & $14.55(26.35)$ & $5.47 *$ \\
\hline Coping & $4.07(5.89)$ & $15.36(28.60)$ & $6.81^{*}$ \\
\hline Self perception & $0.89(1.30)$ & $2.03(3.26)$ & $4.6^{*}$ \\
\hline Leisure time & $9.43(1.26)$ & $1.85(4.15)$ & $4.74 *$ \\
\hline Work & $0.87(1.54)$ & $6.21(13.77)$ & $6.84^{*}$ \\
\hline Money & $0.07(0.25)$ & $1.27(3.55)$ & $5.32 *$ \\
\hline Retirement & $0.11(0.38)$ & $0.15(0.57)$ & 0.16 \\
\hline Social relation & $0.74(1.45)$ & $6.67(14.76)$ & $7.36^{*}$ \\
\hline Biography & $0.24(0.64)$ & $1.58(4.68)$ & 3.67 \\
\hline Comments on forum & $4.43(7.89)$ & $8.27(12.65)$ & $2.75(1.77)$ \\
\hline Offline contacts & $2.39(5.23)$ & $2.21(3.75)$ & $0.03(1.77)$ \\
\hline \multicolumn{4}{|c|}{ Emotional quality of postings } \\
\hline Positive & $6.46(10.36)$ & $18.48(28.28)$ & $7.04 *$ \\
\hline Negative & $3.65(4.15)$ & $9.39(19.73)$ & $3.69(p=0.06)$ \\
\hline Neutral & $18.41(30.36)$ & $46.21(84.29)$ & $4.25^{*}$ \\
\hline Destructive & $0.17(0)$ & $0.79(0)$ & 1.56 \\
\hline \multicolumn{4}{|c|}{ Number of postings related to interaction } \\
\hline Group cohesion & $0.63(1.47)$ & $2.61(3.59)$ & $11.49 *$ \\
\hline Self-Disclosure & $6.67(8.31)$ & $14.91(27.18)$ & $3.75(\mathrm{p}=0.06)$ \\
\hline Emotional support & $2.96(5.48)$ & $8.52(14.28)$ & $5.80^{*}$ \\
\hline Information & $1.11(2.58)$ & $2.42(5.51)$ & n.s. \\
\hline
\end{tabular}

significance: $* \mathrm{p}<0.05, * * \mathrm{p}<0.01$ 
higher rates of 'positive' and 'neutral' comments in the $\mathrm{TF}$ and no significant difference for neutral or destructive comments. The participation of the moderator increases the number of postings, but does not make a difference in respect to their quality, as negative or destructive statements do also increase.

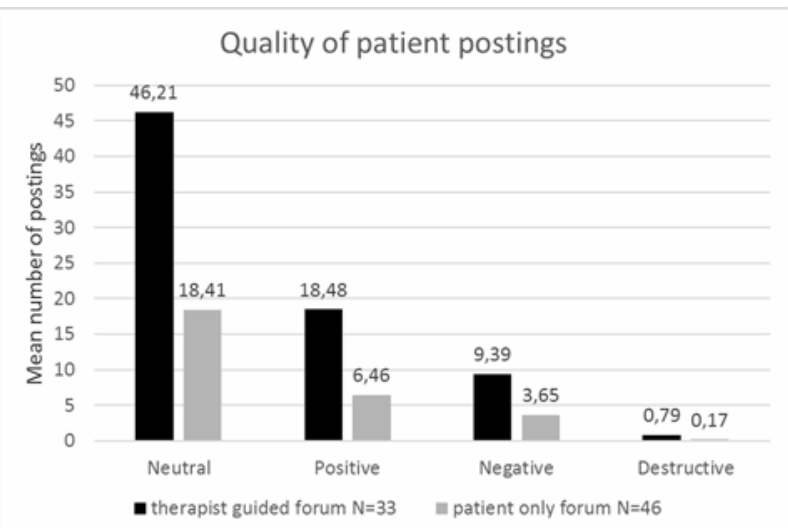

Figure 1. Quality of patient postings in PF and TF

\section{DISCUSSION}

This observational and comparative study promotes an insight into the utilization, the type of patient interaction, and the risks of negative exchanges between patients in an internet forum after patients had been in inpatient treatment for non-psychotic mental disorders. It can help to understand, what is going on in such patient encounters and help to understand the dynamics of self help groups. Such information is of importance for health professionals who must advise their patients on the pros and cons of self help groups in general and internet encounters in particular.

The rate of participation is about $8 \%$ of all invited patients, i.e. more than $90 \%$ did not accept the offer to stay in contact with other patients whom they got to know during inpatient treatment. This is similar or even somewhat higher in comparison to rates which have been reported for face-to-face-self help groups after inpatient treatment (Höflich et al. 2007). Although patients had already participated in face-to-face self help groups, during their inpatient stay the majority of patients still did not participate in the internet forums. These are no means to provide regular care after an inpatient stay but may rather be indicated for selected subgroups only. Our data confirm the general knowledge that internet proficiency, being younger, better educated and male, helps to use these media (Möller 2006, Hausner et al. 2008).

The results show that such a self help patient forum does not lead to a continuous aftercare and interaction between patients. Patients are obviously shy and prefer to read or respond, instead of bringing up their own problems or topics. The moderation does somewhat increase the rate of interaction and also of positive and health related comments. Still, the number of contri- butions is limited. An average of 15 contributions does not allow a real discussion. This again is in line with other reports (Wolf et al. 2006). Also the time period of participation is limited. Patients stay in both forums only about two months. After this time the attraction seems to be lost. The forum does not allow lead to a longer period of contact and care after an inpatient stay.

The analysis of content shows that in both forums most exchanges are health and illness oriented. Comments on personal contacts between participants are rare. No friendship is stimulated. This is true for both groups and even more so for the TF. As the social worker tried to stimulate discussions on health related topics, it is not surprising that there were more illness related comments in the $\mathrm{TF}$.

Of great importance are the findings on the emotional and interactional quality of comments. They are mostly neutral, positive, or supportive. Patients obviously try to be helpful in the encounter with others, and this even more so in the TF (Barrera et al. 2002). But, there are also negative or even detrimental comments, like 'this group is good for nothing' or 'I am better than the rest of you'. They obviously cannot be avoided even by professional moderation. This can result in burdens for the other participants. The conclusion is, that self help groups are not without risks, a problem which is well known from internet users in general under the heading of flaming, cyberbullying or inspiration of suicide (Aboujaoude et al. 2015, Ogburn et al. 2011).

Limitations of the study are that this is an observational cohort study and not a randomized group comparison. We do not know which patients should have participated, which time of contact would be optimal, and whether there were any benefits or possibly negative effects in the long run.

\section{CONCLUSIONS}

The rate of participation in the aftercare internet forum is low and does not lead to a continuous aftercare and interaction between patients. Therapeutic guidance increases the rate of patient contributions, interaction and also positive and health related comments. Patients try to be helpful in the encounter with others but negative interactions occur even in the presence of a moderator.

\section{Acknowledgements: None.}

Conflict of interest: None to declare.

\section{Contribution of individual authors:}

Mochael Linden was the principal investigator.

Carolin Pirsich worked as scientific assistant in the study. Both worked on the mansucript. 


\section{References}

1. Aboujaoude E, Savage MW, Starcevic V, Salame WO: Cyberbullying: Review of an Old Problem Gone Viral. J Adolesc Health 2015; 57:10-8.

2. Alonzo $M$ \& Aiken M: Flaming in electronic сотmunication. Decis Support Syst 2004; 36:205-13.

3. Andersson $G$ \& Titov $N$ : Advantages and limitations of Internet-based interventions for common mental disorders. World Psychiat 2014; 13:4-11.

4. Barrera M Jr, Glasgow RE, McKay HG, Boles SM, Feil EG: Do Internet-based support interventions change perceptions of social support? An experimental trial of approaches for supporting diabetes self-management. Am J Commun Psychol 2002; 30:637-54.

5. Castelein S, Bruggeman R, Van Busschbach JT, Van Der Gaag M, Stant AD, Knegtering $H$ et al.: The effectiveness of peer support groups in psychosis: a randomized controlled trial. Acta Psychiat Scand 2008; 118:64-72.

6. Fullerton CA, Lin H, O'Brien PL, Lenhart GM, Crable EL, Mark TL: Intermediate services after behavioural health hospitalization: effect on rehospitalization and emergency department visits. Psychiatr Serv 2016; Epub ahead of print, February 26.

7. Früh $W$ : Inhaltsanalyse [content analysis], UVK, Konstanz, 2007.

8. Gilat I, Tobin Y, Shahar G: Responses to suicidal messages in an online support group: comparison between trained volunteers and lay individuals. Soc Psych Psych Epid 2012; 47:1929-35.

9. Ginossar T: Online participation: A content analysis of differences in utilization of two online cancer communities by men and women, patients and family members. $J$ Health Commun 2008; 23:1-12.

10. Griffiths KM, Reynolds J, Vassallo S: An Online, Moderated Peer-to-Peer Support Bulletin Board for Depression: User-Perceived Advantages and Disadvantages. JMIR Mental Health 2015; 2:e14.

11. Hausner H, Hajak G, Spießl H: Gender differences in help-seeking behavior on two internet forums for individuals with self-reported depression. Gender Med 2008; 5:181-5.

12. Holtz P, Kronberger N, Wagner W: Analyzing Internet Forums. A Practical Guide. J Media Psychol 2012; 24:55-66.

13. Höflich A, Matzat J, Meyer F, Knickenberg RJ, Bleichner $F$, Merkle $W$ et al.: Inanspruchnahme von Selbsthilfegruppen und Psychotherapie im Anschluss an eine stationäre psychosomatisch- psychotherapeutische Behandlung. Psychotherapy \& Psychosomatics [Utilization of self help groups and psychotherapy after psychosomaticpsychotherapeutic in-patient treatment]. Med Psychol 2007; 57:213-20.

14. Keating DM, Rains SA: Health Blogging and Social Support: A 3-Year Panel Study. J Health Commun 2016; 20:1449-57.
15. Klemm P: Effects of Online Support Group Format (Moderated vs Peer-Led) on Depressive Symptoms and Extent of Participation in Women With Breast Cancer. CIN: Computers, Informatics, Nursing 2012; 30:9-18.

16. Love B, Crook B, Thompson CM, Zaitchik S, Knapp J, LeFebvre L et al.: Exploring psychosocial support online: a content analysis of messages in an adolescent and young adult cancer community. Cyberpsychol Behav Soc Netw 2012; 15:555-9.

17. Mo PK \& Coulson NS: Exploring the communication of social support within virtual communities: A content analysis of messages posted to an online HIV/AIDS support group. Cyberpsychol Behav 2008; 11:371-4.

18. Möller E: (N)ONLINER Atlas, TNS Infratest, München, 2006.

19. Neto DD \& da Silva AC: Characterization of readmissions at a Portuguese psychiatric hospital: An analysis over a 21 month period. Eur J Psychiat 2008; 22:69-76.

20. Ogburn KM, Messias E, Buckley PF: New-age patient communications through social networks. GHP Journal 2011; 33:200.e1-200.e3.

21. Pfeiffer PN, Heisler M, Piette JD, Rogers MAM, Valenstein M: Efficacy of peer support interventions for depression: a meta-analysis. GHP Journal 2011; 33:29-36.

22. Schielein T, Schmid R, Dobmeier M, Spießl H: Selbsthilfe aus dem Cyberspace? [Self-help in the cyberspace]. Psychiat Prax 2008; 35:28-32.

23. Schmädeke S, Bischoff C: Wirkungen smartphonegestützter psychosomatischer Rehabilitationsnachsorge (eATROS) bei depressiven Patienten [Effects of Smartphone-supported Rehabilitation Aftercare (eATROS) for Depressive Patients]. Verhaltenstherapie 2015; 25:277-86.

24. Sendula-Jengic V, Sendula-Pavelic M, Hodak J: Mind in the gap between neural and social networks - cyberspace and virtual reality in psychiatry and healthcare. Psychiatr Danub 2016; 28:100-3.

25. Smith TE, Abraham M, Bolotnikova NV, Donahue SA, Essock SM, Olfson M et al.: Psychiatric inpatient discharge planning practices and attendance at aftercare appointments. Psychiatr Serv 2016, Epub ahead of print, Sep 1.

26. Speed E, Davison C, Gunnell C: The anonymity paradox in patient engagement: reputation, risk and web-based public feedback. Med Humanit 2016; 42:135-40.

27. Wolf M, Maurer WJ, Dogs P, Kordy H: E-Mail in der Psychotherapie-ein Nachbehandlungsmodell via Electronic Mail für die stationäre Psychotherapie. Psychotherapy \& Psychosomatics [E-Mail in psychotherapy. A model for after care in inpatient psychotherapy]. Med Psychol 2006; 56:138-46.

28. Yoo W, Chih MY, Kwon MW, Yang J, Cho E, McLaughlin $B$ et al.: Predictors of the change in the expression of emotional support within an online breast cancer support group: A longitudinal study. Patient Educ Couns 2013; 90:88-95.

Correspondence:

Prof. Michael Linden, $M D, P h D$

Charité University Medicine Berlin, Research Group Psychosomatic Rehabilitation

CBF, Hs II, E01, Hindenburgdamm 30, 12200 Berlin, Germany

E-mail: michael.linden@charite.de 